\title{
Efficacy of Uterine Artery Embolization for Patients with Postpartum Hemorrhage
}

\author{
Young Ho Choi ${ }^{1}$, Yasutaka Baba ${ }^{2 *}$, Shunichiro Ikeda ${ }^{2}$, Young Ho So ${ }^{1}$, \\ Sadao Hayashi ${ }^{2}$, Masayuki Nakajo ${ }^{2}$ \\ ${ }^{1}$ Department of Radiology, SMG-SNU Boramae Medical Center, \\ Seoul, Republic of Korea \\ ${ }^{2}$ Department of Radiology, Graduate School of Medical and Dental Sciences, Kagoshima University, \\ Kagoshima, Japan \\ Email: *yasutaka@m3.kufm.kagoshima-u.ac.jp
}

Received March 1, 2013; revised April 20, 2013; accepted April 28, 2013

Copyright (C) 2013 Young Ho Choi et al. This is an open access article distributed under the Creative Commons Attribution License, which permits unrestricted use, distribution, and reproduction in any medium, provided the original work is properly cited.

\begin{abstract}
Purpose: To investigate the efficacy of uterine arterial embolization (UAE) in patients with post-partum hemorrhage (PPH). Materials and Methods: The subjects were 40 women (mean age, 33 years; age range, 21 - 42 years) who underwent UAE for PPH at two institutes from June 2001 to May 2011. The rates of clinical success (avoidance of hysterectomy) and complications were calculated. Differences in related factors between primary PPH and secondary PPH and between caesarean section and vaginal delivery were examined. The risk factors associated with hysterectomy were also examined. Results: The overall clinical success rate was 90\% (93\% of primary PPH, 77\% of secondary PPH, and 87.5\% of PPH with cesarean section), and the overall complication rate was $10 \%$. There were significant differences in time to PPH $(\mathrm{P}<0.0001)$ and in blood infusion after UAE $(\mathrm{P}=0.0158)$ between subtypes of primary and secondary $\mathrm{PPH}$ and in blood infusion before UAE $(\mathrm{P}=0.0052)$ between delivery methods. The significant factors associated with hysterectomy were cesarean section $(\mathrm{P}=0.02)$, severe $\mathrm{PPH}(>1000 \mathrm{~mL}$ bleeding, $\mathrm{P}=0.03)$, and embolization of non-uterine arteries $(\mathrm{P}=0.02)$.
\end{abstract}

Keywords: Postpartum Hemorrhage; Uterine Artery Embolization; Uterus Preservation

\section{Introduction}

Maternal mortality is very rare in developed countries, but severe conditions associated with delivery still remain [1-3]. Among the complications of delivery, postpartum hemorrhage ( $\mathrm{PPH})$ is the most severe and highly associated with mortality. Regardless of the type (primary or secondary) or severity (moderate or severe) of $\mathrm{PPH}$, stopping the vaginal bleeding and protecting the uterus are the top priorities.

Uterine artery embolization (UAE) is accepted treatment for $\mathrm{PPH}$ in view of its minimal invasiveness, quickness, and efficacy. However, previous reports showed that only $0.000008 \%$ - $14 \%$ of PPH patients underwent UAE, and most PPH patients were treated with medical management, including resuscitation measures, uterotonics, including intravenous administration of oxytocin and, in the case of persistent uterine atony, intravenous administration of sulprostone. In cases of re-

${ }^{*}$ Corresponding author. tained placenta, manual removal was performed. In cases of lacerations and vaginal tears, surgical repair was done [1,4,5]. Primary PPH is defined as $500 \mathrm{ml}$ or more blood loss during the first 24 hours after delivery and secondary $\mathrm{PPH}$ is defined as $500 \mathrm{ml}$ or more blood loss after the first 24 hours following delivery until the $6^{\text {th }}$ week of the puerperium [6,7].

The aim of this study was to investigate the efficacy of UAE in patients with PPH.

\section{Materials and Methods}

All 40 women who underwent UAE for PPH at two institutes were included. All patients were referred to our institutes from affiliated hospitals in order to stop vaginal bleeding after delivery, after failed attempts to stop the vaginal bleeding with oxytocin IV administration for uterine atony, gauze packing, dilatation/curettage for retained placenta, and surgical repair for lacerations/ vaginal tears. Depending on the severity of the patient's 
shock and vital signs, transfusion of blood components was performed as directed by the physician. Informed consent for UAE was obtained from all patients, and institutional review board approval was obtained at each institute for this study.

\subsection{UAE Technique}

UAE procedure was performed by two interventional radiologists (10 years dedicated to IVR procedure) at each institution. After an anatomical survey by aortography, UAE was performed. As stated previously, the UAE procedure [8-15] involves the use of a single 5-French catheter (Cobra; Hanako Medical, Saitama, Japan) to catheterize both uterine arteries. After puncturing the femoral artery to establish an arterial access route, the 5-French catheter was advanced to the contralateral uterine artery with a guidewire (Radiofocus; Terumo, Tokyo, Japan). The catheter was then slowly advanced under fluoroscopic guidance, and a strong torque movement was applied to create a Simmons reverse curve [15]. The shaped catheter was then pulled out into the aorta and placed into the ipsilateral common iliac artery and then into the ipsilateral uterine artery. If selective catheterization of the ipsilateral uterine artery with a 5-French catheter could not be done, a 3-French microcatheter (Renegade; Boston Scientifics, Fremont, CA, USA) was also used to catheterize the ipsilateral uterine artery. Bilateral uterine artery embolization was performed with gelatin sponge (Gelfoam; Pharmacia and Upjohn, New York, NY, USA) when a pseudoaneurysm was not visualized on arteriography. UAE was continued until stasis of blood flow in the uterine arteries was obtained. Basically, if a pseudoaneurysm (extravasation of contrast medium) was seen on arteriography, microcoils (Tornade; COOK, Minneapolis, MN, USA) or N-butyl cyanoacrylate (NBCA) (Histoacryl; B Braun, Melsungen, Germany) was used depending on the severity of the pseudoaneurysm. Otherwise, gelatin sponge or PVA(polyvinyl alcohol) were also used together for UAE in case of pseduaneurysm. Non-uterine arteries, including other internal iliac branches or the ovarian artery, were also embolized when an obvious or suspicious pseudoaneurysm finding was present on arteriography. After embolization, the patients were transferred to the intensive care unit and observed.

\subsection{Assessment}

Technical success was defined as cessation of vaginal bleeding within 24 hours after UAE procedure. Clinical success was defined as avoidance of hysterectomy and cease of vaginal bleeding. In other words, success of embolization was defined as cessation of the hemorrhage (with hemodynamic stability) and the absence of any subsequent surgical procedure. If PPH did not stop after UAE, hysterectomy could be considered. Blood transfusion requirements before and after UAE were calculated. Correlations between subject characteristics and clinical success were evaluated. The two subtypes of PPH (primary vs. secondary) and women who underwent cesarean section were examined separately as well. The definitions of primary and secondary $\mathrm{PPH}$ were as follows: primary $\mathrm{PPH}$ was bleeding during the first 24 hours following delivery, while secondary $\mathrm{PPH}$ was blood loss over $500 \mathrm{ml}$ after the first 24 hours until 6 weeks.

Statistical analysis was performed using a commercially available software package (MedCalc Version 9.5.1.0; MedCalc Software, Mariakerke, Belgium). The chi-square test was used for comparisons of categorical data, and the Mann-Whitney U test was used to compare between two groups. A two-tailed $\mathrm{P}$ value $<0.05$ was considered significant. Clinical data recorded included: transfusion requirements (packed red blood cells: PRBCs) before and after embolization; time from delivery to embolization; and hospital stay. Median values are provided because the data were skewed.

\section{Results}

Forty women (mean age, 33 years; range, 21 - 42 years) underwent UAE, with an overall clinical success rate of 90\% (93\% for primary $\mathrm{PPH}, 77 \%$ for secondary $\mathrm{PPH}$, and $87.5 \%$ for $\mathrm{PPH}$ associated with cesarean section) and an overall complication rate of $10 \%$, including fever ( $\mathrm{n}=$ $5)$, pulmonary edema $(n=2)$, colitis $(n=1)$, and ischemic sciatic neuropathy $(\mathrm{n}=1)$. Mean pre- and postembolization transfusion requirements were 7.6 $\mathrm{U}$ and 4.2 U of PRBCs, respectively. There were significant differences in median blood transfusion requirement after UAE (primary 3 packs, secondary 0 packs; $\mathrm{P}=0.0158$ ) between primary and secondary PPH (Table 1). Meanwhile, there were significant differences in median blood transfusion requirements before UAE (caesarean section 8.5 packs, vaginal delivery 2 packs; $\mathrm{P}=0.0052$ ) and in median hospital stay (caesarean section 60 days, vaginal delivery 19 days; $\mathrm{P}=0.0033$ ) between delivery methods (Table 2). The significant characteristics identified for the cases that required hysterectomy included cesarean section $(\mathrm{P}=0.019915)$, severe $\mathrm{PPH}(>1000 \mathrm{ml}$ bleeding, $\mathrm{P}=0.02604)$, and embolization of non-uterine arteries ( $\mathrm{P}$ $=0.0203)$ (Table 3).

\section{Discussion}

PPH has been defined by the World Health Organization as moderate (blood loss $>500 \mathrm{ml}$ ) and severe (blood loss $>1000 \mathrm{ml}$ ) [16]. Severe PPH is the single most important cause of maternal mortality worldwide [17]. PPH is also classified into primary and secondary PPH subtypes. 
Table 1. Comparison of associated factors between primary and secondary PPH.

\begin{tabular}{cccc}
\hline & $\begin{array}{c}\text { Primary } \\
(\mathrm{n}=31)\end{array}$ & $\begin{array}{c}\text { Secondary } \\
(\mathrm{n}=9)\end{array}$ & $\mathrm{P}$ value \\
\hline Extravasation & 15 & 4 & $\mathrm{P}=0.8645$ \\
Beyond UAE & & 2 & $\mathrm{P}=0.7764$ \\
Delivery methods & 6 & & $\mathrm{P}=0.3952$ \\
Caesarian section & 14 & 2 & \\
Vaginal & 17 & 7 & \\
Time to PPH (hours) & & & \\
Median(range ) & $3(2-24)$ & 408 & $\mathrm{P}<0.0001$ \\
Blood infusion (unit) & & & \\
before UAE & $4(0-45)$ & $4(0-17)$ & $\mathrm{P}=0.5819$ \\
Blood infusion (units) & & & \\
after UAE & $3(0-37)$ & $0(0-4)$ & $\mathrm{P}=0.0181$ \\
Hospital stay (days) & $6(2-60)$ & $7(3-19)$ & $\mathrm{P}=0.7831$ \\
Bleeding stop? & $28(90 \%)$ & $9(100 \%)$ & $\mathrm{P}=0.8014$ \\
Clinical success & & & \\
(avoidance of Hysterectomy) & 29 & 7 & $\mathrm{P}=0.4489$ \\
\hline
\end{tabular}

Note) ${ }^{*}$ Beyond UAE mean that additional extra-uterine arterial embolization for PPH.

Table 2. Comparison of associated factors between caesarian and vaginal delivery.

\begin{tabular}{cccc}
\hline & $\begin{array}{c}\text { Caesarian } \\
(\mathrm{n}=16)\end{array}$ & $\begin{array}{c}\text { Vaginal } \\
(\mathrm{n}=21)\end{array}$ & $\mathrm{P}$ value \\
\hline Extravasation & 10 & 9 & $\mathrm{P}=0.2195$ \\
Beyond UAE & 5 & 3 & $\mathrm{P}=0.2942$ \\
Time to PPH (hours) & & & \\
Median (range) & $\begin{array}{c}4 \\
(0-48)\end{array}$ & $\begin{array}{c}(0-375 \\
\text { Blood infusion (units) }\end{array}$ & $\mathrm{P}=0.5254$ \\
before UAE & 8.5 & $2(0-16)$ & $\mathrm{P}=0.0053$ \\
Blood infusion (units) & & & \\
after UAE & $3(0-45)$ & $2(0-10)$ & $\mathrm{P}=0.087$ \\
Hospital stay (days) & $8(4-60)$ & $5(2-19)$ & $\mathrm{P}=0.0034$ \\
Bleeding stop? & 14 & 23 & $\mathrm{P}=0.7132$ \\
Clinical success & & & \\
(avoidance of Hysterectomy) & 12 & 29 & $\mathrm{P}=0.0409$ \\
\hline
\end{tabular}

Primary PPH is defined as excessive bleeding from the genital tract $(500 \mathrm{ml}$ or more during the first 24 hours
Table 3. Factors associated with clinical failure (hyterectomy).

\begin{tabular}{ccc}
\hline & $\begin{array}{c}\text { Clinical Failure } \\
\text { (Hysterectomy) }\end{array}$ & P value \\
\hline Caesarian section $(\mathrm{n}=16)$ & $4(25 \%)$ & $\mathrm{P}=0.0199$ \\
Severe $\mathrm{PPH}^{*}(\mathrm{n}=17)$ & $4(24 \%)$ & $\mathrm{P}=0.026$ \\
${\text { Beyond } \mathrm{UAE}^{* *}(\mathrm{n}=8)}$ & $3(37.5 \%)$ & $\mathrm{P}=0.020$ \\
\hline
\end{tabular}

Note) ${ }^{*}>1000$ ml bleeding; ${ }^{* *}$ Beyond UAE mean that additional extra-uterine arterial embolization for PPH.

after delivery) [6,7]. Secondary PPH is defined as excessive bleeding from the genital tract, with a blood loss of $1000 \mathrm{ml}$ or more, that occurs after the first 24 hours following delivery until the $6^{\text {th }}$ postpartum week $[6,7]$. Primary and secondary PPH typically have different clinical presentations, causes, and maternal mortality rates $[18,19]$; thus, the clinical success rate was higher for primary PPH (93\%) than for secondary PPH (77\%) in the present study. Uterine atony is the most common cause of primary PPH [20,21]. Meanwhile, secondary PPH is caused by placental fragments and subsequent inflammation or hematoma [7]. The difference in the clinical success rate between primary and secondary PPH appears to depend on prolonged inflammation (endometritis) or hematoma, despite vaginal bleeding having stopped.

Among other differences between primary and secondary PPH, time to PPH and blood transfusion after UAE were significantly different factors. The first result was predictable, but the latter result was unexpected. A smaller amount of blood infusion after UAE suggests that patients with secondary PPH may recover from hypovolemia sooner than patients with primary PPH.

The present results showed that the significant factors associated with hysterectomy were cesarean section $(\mathrm{P}=$ $0.019915)$, severe PPH ( $>1000 \mathrm{ml}$ bleeding, $\mathrm{P}=0.02604$ ), and embolization of non-uterine arteries $(\mathrm{P}=0.0203)$.

Previous reports suggested that iatrogenic pseudoaneurysm after cesarean section is an increasingly recognized cause for secondary PPH [11,22,23]. However, the present results did not show a significant difference for pseudoaneurysm or type of PPH (primary or secondary: $\mathrm{P}=0.73$ ).

Referring to the embolic agents, gelatin sponge is widely used for UAE of PPH [8,10,12,13] because of its highly hemostatic effect and low risk of ischemic complications. So far, gelatin sponge has been a useful embolic agent and considered a temporary occlusion. However, both coils and NBCA are useful embolic agents when a pseudoaneurysm is visualized on arteriography, because gelatin sponge embolization alone may not achieve prolonged hemostasis.

In general, the overall complication rate was $10 \%$, and most complications were mild, including abdominal pain 
or fever that could be treated conservatively. Severe complications were noted in one patient (ischemic sciatic neuropathy and skin necrosis). In this patient, extravasation from the uterine artery was recognized, and UAE was attempted with NBCA following gelatin sponge embolization. The additional NBCA may have increased the risk of ischemic complications in this patient.

This study has several limitations, because it includes only a small group of patients, diverse indications, multiple operators, and different techniques of UAE. Therefore, we think it is necessary to launch a prospective clinical study of UAE study for $\mathrm{PPH}$ in order to avoid the bias as described above.

In conclusion, the overall clinical success rate was 90\% (93\% of primary $\mathrm{PPH}, 77 \%$ of secondary $\mathrm{PPH}$, and $87.5 \%$ of $\mathrm{PPH}$ with cesarean section), and the overall complication rate was $10 \%$. Cesarean section $(\mathrm{P}=$ 0.019915), severe PPH (>1000 ml bleeding, $\mathrm{P}=0.02604)$, and embolization of non-uterine arteries $(P=0.0203)$ were highly associated with the need for hysterectomy. However, UAE for PPH has a high clinical success rate and a low complication rate. Therefore, uterine artery embolization should be considered as the first treatment of choice for $\mathrm{PPH}$.

\section{REFERENCES}

[1] C. L. Roberts, J. B. Ford, C. S. Algert, J. C. Bell, J. M. Simpson and J. M. Morris, "Trends in Adverse Maternal Outcomes during Childbirth: A Population-Based Study of Severe Maternal Morbidity,” BMC Pregnancy and Childbirth, Vol. 9, No.1, 2009, p. 7. doi:10.1186/1471-2393-9-7

[2] W. H. Zhang, S. Alexander, M. H. Bouvier-Colle and A. Macfarlane, "Incidence of Severe Pre-Eclampsia, Postpartum Haemorrhage and Sepsis as a Surrogate Marker for Severe Maternal Morbidity in a European Population-Based Study: The MOMS-B Survey,” BJOG: An International Journal of Obstetrics \& Gynaecology, Vol. 112, No. 1, 2005, pp. 89-96. doi:10.1111/j.1471-0528.2004.00303.x

[3] C. G. Sosa, F. Althabe, J. M. Belizan and P. Buekens, "Risk Factors for Postpartum Hemorrhage in Vaginal Deliveries in a Latin-American Population,” Obstetrics \& Gynecology, Vol. 113, No. 6, 2009, pp. 1313-1319.

[4] H. A. Mousa and Z. Alfirevic, "Major Postpartum Hemorrhage: Survey of Maternity Units in the United Kingdom,” Acta Obstetricia et Gynecologica Scandinavica, Vol. 81, No. 8, 2002, pp. 727-730. doi:10.1034/j.1600-0412.2002.810807.x

[5] H. A. Mousa and Z. Alfirevic, "Treatment for Primary Postpartum Haemorrhage,” Cochrane Database of Systematic Reviews, No. 1, 2003, Article ID: CD 003249.

[6] R. M. Rome, "Secondary Postpartum Haemorrhage," BJOG: An International Journal of Obstetrics \& Gynaecology, Vol. 82, No. 4, 1975, pp. 289-292.

doi:10.1111/j.1471-0528.1975.tb00636.x
[7] P. A. King, S. J. Duthie, Z. G. Dong and H. K. Ma, "Secondary Postpartum Haemorrhage," Australian and New Zealand Journal of Obstetrics and Gynaecology, Vol. 29, No. 4, 1989, pp. 394-398. doi:10.1111/j.1479-828X.1989.tb01776.X

[8] J. P. Pelage, O. Le Dref, P. Soyer, D. Jacob, M. Kardache, H. Dahan, D. Repiquet, D. Payen, J. B. Truc, J. J. Merland and R. Rymer, "Life-Threatening Primary Postpartum Hemorrhage: Treatment with Emergency Selective Arterial Embolization,” Radiology, Vol. 208, No. 2, 1998, pp. 359-362.

[9] J. P. Pelage, O. Le Dref, D. Jacob, P. Soyer, D. Herbreteau and R. Rymer, "Selective Arterial Embolization of the Uterine Arteries in the Management of Intractable Post-Partum Hemorrhage," Acta Obstetricia et Gynecologica Scandinavica, Vol. 78, No. 8, 1999, pp. 698-703. doi:10.1080/j.1600-0412.1999.780807.x

[10] J. P. Pelage, P. Soyer, D. Repiquet, D. Herbreteau, O. Le Dref, E. Houdart, D. Jacob, M. Kardache, P. Schurando, J. B. Truc and R. Rymer, "Secondary Postpartum Hemorrhage: Treatment with Selective Arterial Embolization," Radiology, Vol. 212, No. 2, 1999, pp. 385-389.

[11] D. M. Biko, J. F. Spanier, M. Nagamine, L. Dwyer-Joyce and D. S. Ball, "Persistent Secondary Postpartum Hemorrhage after Uterine Artery Embolization," Journal of Vascular and Interventional Radiology, Vol. 20, No. 2, 2009, pp. 279-281. doi:10.1016/j.jvir.2008.10.016

[12] M. E. Simons, R. C. Windrim and J. C. Kingdom, "Arterial Embolization for Primary Postpartum Hemorrhage," Journal of Vascular and Interventional Radiology, Vol. 20, No. 8, 2009, pp. 1036-1045. doi:10.1016/j.jvir.2009.04.070

[13] S. Ganguli, M. S. Stecker, D. Pyne, R. A. Baum and C. M. Fan, "Uterine Artery Embolization in the Treatment of Postpartum Uterine Hemorrhage," Journal of Vascular and Interventional Radiology, Vol. 22, No. 2, 2011, pp. 169-176. doi:10.1016/j.jvir.2010.09.031

[14] L. Sentilhes, A. Gromez, E. Clavier, B. Resch, E. Verspyck and L. Marpeau, "Predictors of Failed Pelvic Arterial Embolization for Severe Postpartum Hemorrhage," Obstetrics \& Gynecology, Vol. 113, No. 5, 2009, pp. 992999.

[15] J. P. Pelage, P. Soyer, O. Le Dref, H. Dahan, J. Coumbaras, M. Kardache and R. Rymer, "Uterine Arteries: Bilateral Catheterization with a Single Femoral Approach and a Single 5-F Catheter-Technical Note,” Radiology, Vol. 210, No. 2, 1999, pp. 573-575.

[16] WHO, “World Health Report,” Geneva, 2005.

[17] F. Donnay, "Maternal Survival in Developing Countries: What Has Been Done, What Can Be Achieved in the Next Decade,” International Journal of Gynecology \& Obstetrics, Vol. 70, No. 1, 2000, pp. 89-97. doi:10.1016/S0020-7292(00)00236-8

[18] C. A. Combs, E. L. Murphy and R. K. Laros, "Factors Associated with Hemorrhage in Cesarean Deliveries," $\mathrm{Ob}$ stetrics \& Gynecology, Vol. 77, No. 1, 1991, pp. 77-82.

[19] C. A. Combs, E. L. Murphy and R. K. Laros Jr., "Factors Associated with Postpartum Hemorrhage with Vaginal Birth,” Obstetrics \& Gynecology, Vol. 77, No. 1, 1991, 
pp. 69-76.

[20] M. Varner, "Postpartum Hemorrhage," Critical Care Clinics, Vol. 7, No. 4, 1991, pp. 883-897.

[21] P. Jouppila, “Postpartum Haemorrhage,” Current Opinion in Obstetrics and Gynecology, Vol. 7, No. 6, 1995, pp. 446-450. doi:10.1097/00001703-199512000-00008

[22] S. Samad, P. Jonetzko, A. P. Hawkins, J. Booth, G. Thorpe-Beeston and R. Marwood, “An Unusual Cause of De- layed Postpartum Haemorrhage Following Caesarean Section,” Emergency Medicine Journal, Vol. 26, No. 8, 2009, pp. 621-622. doi:10.1136/emj.2008.066407

[23] W. Henrich, I. Fuchs, A. Luttkus, S. Hauptmann and J. W. Dudenhausen, "Pseudoaneurysm of the Uterine Artery after Cesarean Delivery: Sonographic Diagnosis and Treatment," Journal of Ultrasound in Medicine, Vol. 21, No. 12, 2002, pp. 1431-1434. 